\title{
A Retrospective Analysis of Breast Cancer at BPKMCH, Nepal
}

\author{
Chin Bahadur Pun, Sadina Shrestha, Ranjan Raj Bhatta, Greta Pandey, Suraj Uprety, Shankar Bastakoti, \\ Ishan Dhungana, Nandita Jha \\ Department of Pathology, B.P. Koirala Memorial Cancer Hospital, Bharatpur, Chitwan, Nepal
}

\begin{abstract}
Introduction: Breast cancer is the most common cancer and also the leading cause of cancer related mortality in women worldwide which impact 2.1 million women each year. Breast cancer rates are increasing in nearly every region globally.
\end{abstract}

Methods: This was retrospective study at Department of Pathology in B P Koirala Memorial Cancer Hospital effective from 15 April 2018 to 14 April 2019. All the data were retrieved and analyzed.

Results: Total 205 breast cancer cases were analyzed, among them 198 cases were females accounting $96.5 \%$ and 7 cases were males accounting $3.5 \%$.

Among 205 cases, 181 ( 88.6\% ) cases were invasive ductal Carcinoma No Special Type. Majority of cases 111 (54\%) were diagnosed with Nottingham grading system grade II of breast cancer.

According to our study breast cancer was most common in the age group $41-50$ years ( $32.2 \%$ ).

Conclusion: Breast cancer is more common in females than in males. Most common affected age group was 4150 years. Most common histological type was invasive ductal carcinoma NST. Similarly, left sided breast cancer was more common than right.

Keywords: Breast Cancer, Pathology, Surgery, Radiation Therapy

\section{Introduction:}

Breast cancer is a group of diseases in which cells in breast tissue change and divide uncontrolled, typically resulting in a lump or mass. Most breast cancers begin in the lobules (milk glands) or in the ducts that connect the lobules to the nipple. Breast cancer is the most common cancer and also the leading cause of cancer mortality in women worldwide. Approximately 1.38 million new breast cancer cases were diagnosed in 2008 with almost half of all breast cancer cases and nearly $60 \%$ of deaths occurring in lower income countries. ${ }^{1,2}$

Globally, breast cancer impacting 2.1 million women each year, and also causes the greatest number of cancer- related deaths among women. In 2018, it is estimated that 627,000 women died from breast cancer - that is approximately $15 \%$ of all cancer deaths among women. While breast cancer rates are increasing in nearly every region globally. ${ }^{1,2}$

The breast cancer in females in the Western world, with a lifetime risk of the order of $1 / 10$. Similarly about 1 in 8 U.S. women (about 12\%) will develop invasive breast cancer over the course of her lifetime. ${ }^{2}$

High-income countries (HICs) have made the most progress in improving breast cancer outcomes attributable to the combination of improved earlier

\section{Correspondence}

Dr. Chin Bahadur Pun, Senior Consultant Pathologist, 9845965498, chinbahadurpun@hotmail.com Bharatpur, Chitwan, Nepal 
detection and effective adjuvant therapies. By contrast, breast cancer is an increasingly urgent problem in lowand middle-income countries (LMICs). ${ }^{3}$

\section{Methods}

This is retrospective study at Department of Pathology in B P Koirala Memorial Cancer Hospital effective from 15 April 2018 to 14 April 2019. This study included the patients who were operated at $\mathrm{BPKMCH}$ or referred cases from elsewhere, but the specimen was processed and reported at BPKMCH. All the data were retrieved and analyzed.

\section{Results}

Total 205 breast cancer cases were analyzed, among them 198 cases were females accounting $96.5 \%$ and 7 cases were males accounting $3.5 \%$.

Among 205 cases, As per WHO Cassification 20194, $182(88.9 \%)$ cases were invasive breast Carcinoma of No Special Type, in addition histologic subtype 4 (1.9\%) cases were of medullary pattern, 5 (2.4\%) cases were malignant phylloides tumour, 4 (1.9\%) cases were invasive lobular carcinoma, $4(1.9 \%)$ cases were Metaplastic carcinoma, $3(1.4 \%)$ cases were Paget's disease of nipple with ductal carcinoma in situ, 2 (0.9\%) cases were mucinous carcinoma, $1(0.4 \%)$ case was invasive papillary carcinoma.

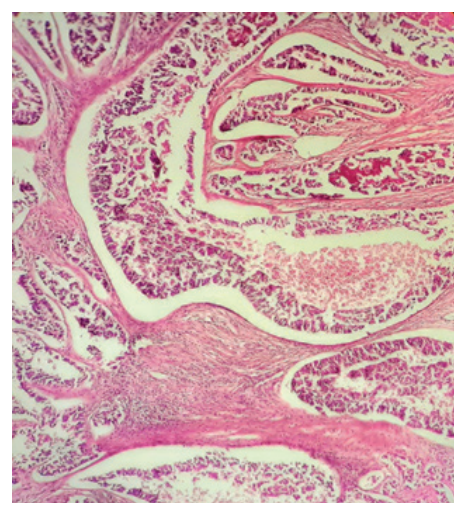

Figure 1 : Tumor cell in lobules and tubules with comedo-necrosis (10x, H\&E)

Regarding grading of tumour, 111 (54\%) cases were Grade II, 49 (24\%) cases were Grade III, and 45 (22\%) cases were Grade I.

Ethnicity-wise Terai/ Madhes, were commonest with
82 (40.1\%) cases, 55 (26.9\%) cases were from Brahman/ Chhetri, 54 ( 26.4\% ) cases were from Janajati/Newar, 14 (6.8\% ) cases were from Dalit community.

Considering tumour size (See table 2) 119 (58.9\%) cases were T2, (17.8\%) cases were T3, 25 (12.4\%) cases were T4, 22 ( $10.9 \%)$ cases were $\mathrm{T} 1$ group.

Lymphnode metastasis was observed in 128 (63.4\%) and $74(36.6 \%)$ cases were devoid of lymphnode metastasis. Out of 128, 63 (31.2\%) cases were N1, 43 (21.3\%) cases were N2, 22 (10.9\%) cases were N3 type.

Table 1: Age-wise breast cancer cases were as follows

\begin{tabular}{|l|l|l|}
\hline \multicolumn{1}{|c|}{ Age group } & Breast Cancer $(\mathbf{n})$ & Percentage \\
\hline Less than 20 Years & - & - \\
\hline 21-30 Years & 9 & $4.4 \%$ \\
\hline 31-40 Years & 46 & $22.4 \%$ \\
\hline 41-50 Years & 66 & $32.2 \%$ \\
\hline 51-60 Years & 52 & $25.4 \%$ \\
\hline 61-70 Years & 21 & $10.2 \%$ \\
\hline More than 70 Years & 11 & $5.4 \%$ \\
\hline Total & 205 & $100 \%$ \\
\hline
\end{tabular}

Table 2: Distribution as per tumor size.

\begin{tabular}{|l|l|}
\hline \multicolumn{1}{|c|}{ Tumor size } & Frequency (\%) \\
\hline T1(less than $2 \mathrm{~cm})$ & $22(10.9 \%)$ \\
\hline T2 $(2-5 \mathrm{~cm})$ & $119(58.9 \%)$ \\
\hline T3 $(>5 \mathrm{~cm})$ & $36(17.8 \%)$ \\
\hline $\begin{array}{l}\text { T4(Direct extension to skin or chest } \\
\text { wall) }\end{array}$ & $25(12.4 \%)$ \\
\hline
\end{tabular}

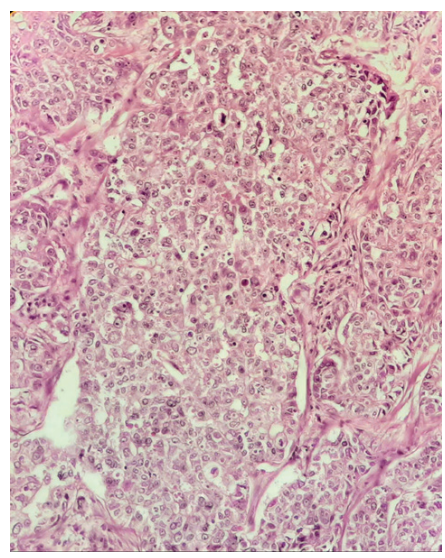

Figure 2 : Tumor cells pleomorphic arranged in sheets and vague tubules $(40 \mathrm{x}, \mathrm{H} \& \mathrm{E})$ 


\section{Discussion}

Breast cancer is a heterogeneous disease, comprising multiple entities associated with distinctive histological and biological features, clinical presentations and behaviours and responses to therapy. ${ }^{3}$

This study comprises 205 breast cancer patients of which 198 (96.5\%) were females and 7 (3.5\%) were males, which is comparable to the study published by Pathak, $\mathrm{R}$ et al, in which females cases were $97.3 \%$ and male cases were $2.7 \% .^{5}$

According to the study carried by $S$ Jamal et al, carcinoma of breast is one of the less frequent malignancies in males. In their study 50 cases of malignant tumours of male breast diagnosed during a 10 years period (19801989) were analysed retrospectively. One male breast was involved for every 33 female cases. The peak incidence was between 5 th to 7 th decade with mean age of 58.54 years. Histologically, the infiltrating duct carcinoma (grade III) was the predominant lesion. ${ }^{6}$

According to our study breast cancer was most common in the age group 41-50 years (32.2\% ). Similarly Chavan, $\mathrm{R}$ et al, encountered maximum breast cancer in the agegroup $40-50$ years (38\% ). ${ }^{7}$

Shrestha JS et al did study, among 3270 total cancer patients, among them 5.59\% (183 patients) had breast cancer. Age range 40 to 49 was the most affected age group comparable to WHO data on the Nepal breast cancer status. The minimum age was 22 years and the maximum was 82 years. Left sided breast (51\%) cancer was more common, followed by right sided (44\%) and bilateral (4\%). This result is comparable to the result of the similar study done in India where left sided cancer was more common than right sided. ${ }^{8}$ In our study minimum age was 23 years and the maximum age was 92 years. Left sided breast cancer cases were 111 (54.15\%) and right sided breast cancer cases were 94 ( $45.85 \%)$. So our study revealed that left sided breast cancer was more common than right sided breast cancer.

Breast cancers can be classified into biologically and clinically meaningful subgroups according to histological grade. Estrogen receptor (ER), progesterone receptor (PR), and human epidermal growth factor receptor-2 (HER2/neu) are immunohistochemical markers of prognosis as well as predictors of response to therapy.9
Histological type, on the other hand, refers to the growth pattern of the tumours. The histological diversity of adenocarcinoma in the breast has long fascinated pathologists, who have identified specific morphological and cytological patterns that were consistently associated with distinctive clinical presentations and/or outcomes. These patterns are called 'histological types'. The commonest type of breast carcinoma is invasive ductal carcinomas not otherwise specified (IDC-NOS) or of no special type (IDC-NST). ${ }^{3}$

In our study we did grading based on Nottingham grading system. According to our study 111 ( 54\% ) cases were Grade II cancer, 49 ( $24 \%$ ) cases were Grade III cancer and 45 ( 22\% ) cases were Grade I cancer. Which is comparable to the study carried by Chavan, R., \& Prasad A, in which they found out of 150 patients, 55\% cases were diagnosed with Nottingham grading system grade II of breast cancer. ${ }^{7}$

According to our study most common histological type was invasive ductal carcinoma NST 182 ( $88.9 \%$ ) cases, followed by malignant phylloides tumour $5(2.4 \%)$ cases, invasive lobular carcinoma ${ }^{4}(1.9 \%)$ cases, medullary carcinoma $4(1.9 \%)$ cases, squamous cell carcinoma $4(1.9 \%)$ cases, Paget's disease of nipple with ductal carcinoma in situ $3(1.4 \%)$ cases, mucinous carcinoma $2(0.9 \%)$ cases, invasive papillary carcinoma $1(0.5 \%)$ case respectively. Similarly, $58.9 \%$ cases were at T2 stage, $17.8 \%$ cases were at $\mathrm{T} 3$ stage, $12.4 \%$ cases were at $\mathrm{T} 4$ stage and $10.9 \%$ cases were at $\mathrm{T} 1$ stage. $36.6 \%$ cases were at N0 stage, $31.2 \%$ cases were at N1 stage, $21.3 \%$ cases were at N2stage and $10.9 \%$ cases were at N3 stage. These findings suggest that most of the cases were in advanced stage which is similar to the finding by a study by Grethe Albrektsen et al.

Pathak, $\mathrm{R}$ et al did study comprising 112 breast cancer patients of which invasive ductal carcinoma no specific type (fig.1,2)was the most common type of breast carcinoma, 84 cases accounting $75 \%$ of total cases. Carcinoma with medullary features was second most common (6 cases) comprising 5.4\% cases followed by lobular, papillary, apocrine, mucinous and NST mixed types. Grade II tumors were most frequent grade observed in $76.79 \%$ cases followed by Grade I (12.50\%) and Grade III (10.71\%). 
Breast cancer has emerged as the second more prevalent malignancy in women in Nepal. But the hospital records show that Nepali women seek medical help when the disease is already in an advanced stage. ${ }^{11}$

Factors responsible for the general delayed diagnosis are lack of knowledge, limited breast cancer screening programs, limited health care facilities and sociocultural barriers. The government should foster novel policies to establish effective nationwide cancer literacy programmes, as well as engagements with communitylevel, national and international organizations and the healthcare system. ${ }^{12}$

In order to improve breast cancer outcomes and survival, early detection is critical. There are two early detection strategies for breast cancer: early diagnosis and screening. Limited resource settings with weak health systems where the majority of women are diagnosed in late stages should prioritize early diagnosis programmes based on awareness of early signs and symptoms and prompt referral to diagnosis and treatment.

\section{Conclusion}

Breast cancer is more common in females than in males. Most common affected age group was 41-50 years. Similarly, our study revealed that left sided breast cancer was more common than right sided breast cancer. Majority of cases was Invasive Breast Carcinoma, No special type with Nottingham grading system grade II. Most common histological type was invasive ductal carcinoma NST and mostly cases were in advanced stage. In order to improve breast cancer outcomes and survival, early diagnosis and screening should be done.

\section{References}

1. World Health Organisation, 2018 Topic: Cancer; Breast Cancer [Internet]https://www.who.int/cancer/ prevention/diagnosis-screening/breast-cancer

2. Sigurdur Ingvarsson: Breast cancer: introduction, Seminars in Cancer Biology 2001;11(5):323-326.

3. Anne-Lise Børresen-Dale, Therese Sørlie, Vessela N. Kristensen, Britta Weigelt, Felipe C, Geyer, Jorge S, Reis-Filhocorresponding: Histological types of breast cancer: How special are they? Mol Oncol. 2010 Jun; 4(3): 192-208.

4. WHO Classification of Tumors Editorial Board, Breast tumors, Lyon(France); International Agency for research on Cancer; 2019(WHO classification of tumor series, 5th ed : vol 2) https://publications. iarc.fr/581

5. BO Anderson: Abstract IS-1: IS-1 Breast cancer initiative 2.5 (BCI2.5): A framework for systematic improvement in global breast cancer outcomes. Cancer Res 2017;77(4 Suppl):Abstract nr IS-1.

6. Britta Weigelt 1, Felipe C Geyer, Jorge S Reis-Filho: Histological types of breast cancer: how special are they? Review Mol Oncol. 2010 Jun;4(3):192-208.

7. Pathak, R., Jha, A., Neupane, P., Chalise, S., \& Basnyat, A: Histopathological evaluation of carcinoma of breast. Journal of Pathology of Nepal, 2016; 6(11): 922-927.

8. S Jamal, S Mushtaq, I A Malik, A H Khan, N Mamoon: Malignant tumours of the male breast-a review of 50 cases. J Pak Med Assoc. 1994 Dec;44(12):275-7.

9. Chavan, R., \& Prasad, A: Clinicopathological study of breast diseases: A hospital-based study. Journal of Pathology of Nepal, 2019; 9(1): 1460-1463.

10. Shrestha JS, Shrestha A, Shrestha S, Shrestha S, Sharma TR, et al: Epidemiology and Clinical Profile of Breast Cancer in Central Nepal. Ann Breast Cancer Res 2016;1(1): 1005.

11. Chand P, Garg A, Singla V, Rani N. Evaluation of Immunohistochemical Profile of Breast Cancer for Prognostics and Therapeutic Use. Niger J Surg. 2018 Jul-Dec;24(2):100-106. doi: 10.4103/njs.NJS_2_18. PMID: 30283220; PMCID: PMC6158994.)

12. Grethe Albrektsen, Ivar Heuch, Steinar Thoresen: Histological type and grade of breast cancer tumors by parity, age at birth, and time since birth: a register-based study in Norway. BMC Cancer. 2010 May 21;10:226. doi: 10.1186/1471-2407-10-226.

13. Singh YP, Sayami P: Management of Breast Cancer in Nepal. JNMA. 2009; 48: 252-257.

14. Mohan Giri, Mamata Giri, Rabin Jung Thapa, Bibhuti Upreti, Bijay Pariyar: Breast Cancer in Nepal: Current status and future directions. Biomed Rep. 2018 Apr; 8(4): 325-329. 